Research Article

\title{
Impact of Strontium and Krypton Release from Ghana's MNSR following a Conjectural Accident Scenario
}

\author{
S. A. Birikorang $\mathbb{D}^{1,2}$ R. G. Abrefah, ${ }^{1,2}$ H. K. Obeng, ${ }^{1,3}$ and K. Gyamfi $\mathbb{C}^{1,3}$ \\ ${ }^{1}$ University of Ghana, School of Nuclear and Allied Sciences, P. O. Box AE1, Atomic Energy, Accra, Ghana \\ ${ }^{2}$ Nuclear Regulatory Authority, P. O. Box AE50, Atomic Energy, Accra, Ghana \\ ${ }^{3}$ Ghana Atomic Energy Commission, P. O. Box LG80, Legon, Accra, Ghana
}

Correspondence should be addressed to S. A. Birikorang; sa.birikorang@gmail.com

Received 23 July 2019; Revised 24 October 2019; Accepted 5 November 2019; Published 1 December 2019

Academic Editor: Michael I. Ojovan

Copyright (c) 2019 S. A. Birikorang et al. This is an open access article distributed under the Creative Commons Attribution License, which permits unrestricted use, distribution, and reproduction in any medium, provided the original work is properly cited.

\begin{abstract}
Accidental release of gaseous or liquid effluents is a critical issue and of a greater concern to the nuclear industry when it comes to the protection of the public and the environment. The emphasis becomes paramount when the release involves particulate of radiation particles. This paper provides a comprehensive insight report on an account of a research investigation carried out in addressing a radiological safety issue of Ghana's Miniature Neutron Source Reactor (MNSR) during its core conversion project. The amounts of Strontium-90 (Sr-90) and Krypton-85 (Kr-85) effluents presumably released from the reactor hall to the surroundings and the consequential emission radiation to the working area within a $200 \mathrm{~m}$ radius were analyzed for a six-month working period. The objective was to estimate specifically the approximate total effective dose equivalent (TEDE) of Sr-90 and Kr85 by considering a conjectural accident scenario using a well-recognized and user-friendly known atmospheric dispersion model before the preparatory period. The maximum TEDE value recorded at a ground deposition value of $4.6 \mathrm{E}-01 \mathrm{kBq} / \mathrm{m}^{2}$ was approximately $1.80 E-02 \mathrm{mSv}$ and $4.90 E-4 \mathrm{mSv}$ for $\mathrm{Sr}-90$ and $\mathrm{Kr}-85$, respectively, at a maximum distance of $0.1 \mathrm{~km}$ from the source. The estimated dose values recorded were found to be within the recommended regulatory safety limits of $50 \mathrm{mSv}$ for onsite workers and $1 \mathrm{mSv}$ for the general public. No adverse effect was experienced with respect to human health and the environment.
\end{abstract}

\section{Introduction}

In Ghana, the only nuclear research reactor currently in operation is the Ghana Research Reactor-1 (notably termed as "GHARR-1"). The reactor is a miniature neutron source reactor of a Chinese origin. It is a very compact kind of research reactor fueled with High Enriched Uranium (HEU) [1]. Most research and test reactors use uranium aluminum alloyed fuel which has been preferred in the past. The reason is that HEU ( $\sim 90 \%$ U-235) allows for denser reactor core design. The design helps to attain a high value of core excess reactivity which gives room for varieties of experiments. It has also been found to keep the core life cycle length considerably large. Aside from its various benefits, HEU presents a very distinctive challenge from the nuclear security perspective. Because of its nuclear unique properties,
HEU can be relatively used easily in a much simple way for nuclear explosive device [2]. It has therefore become significantly dangerous with regard to potential use by state and nonstate actors with limited nuclear weapon expertise. In addition, due to the fact that HEU has a 20 percent or higher concentration of Uranium-235 or is a fissile material of 80 percent or more Uranium-235, it has been considered as weapons-grade [3].

The major issue associated with civilian research facilities is usually the lack of sufficient protection from the security point of view. Appreciating the intrinsic security risks associated with the lasting or continues use of HEU and the nuclear proliferation risks associated with these activities is very important. This thought boggling has initiated a wakeup call for most international bodies. The United States Congress, as well as foreign policy makers, has formally 
introduced the concept of conversion from HEU to LEU to address the concerns of proliferation of HEU for weapons purposes to nonnuclear weapons states (NNWS), other nations outside of the Nonproliferation Treaty (NPT), and nonstate actors [4]. To act without delay and with greater urgency, a team of noble organization led by the United States and other international communities (like the International Panel of Fissile Materials (IPFM) and the IAEA) and with the support of many IAEA's member states was created with the sole aim of reducing the use of HEU in civilian application [5]. Thus, there is a call for all HEU fuel to be converted to Low Enriched Uranium (LEU) fuel. This call has compelled Ghana to convert its first nuclear research reactor from HEU fuel to LEU fuel. This global effort has been made for core enrichment reduction of U-235 from approximately $90 \%$ to about $20 \%$, an activity under the Reduced Enrichment for Research and Test Reactor (RERTR) program return. The RERTR has a target of converting about $105 \mathrm{HEU}$ fueled reactor to the corresponding LEU configurations [6].

To have a comprehensive view of the radiological effect associated with HEU fuel prior to core conversion process, it is usually essential to perform impact assessment. Impact assessment on radiological incidence for possible release of various kinds of radionuclides in the core to the environment helps in estimating possible amount of radiation doses. This is very essential because it is a way of predicting possible radiation effect on the people and how to protect the radiation workers and the public. The credibility of the whole core conversion program is very much dependent on the safety measure that has been considered and radiation dose assessment for possible release of viable radionuclide in the reactor core. More importantly, from regulatory perspective, addressing possible radiological consequences has been tagged as the hallmark of a nuclear regulator. With this aim and in fulfillments of regulatory requirements, this paper provides a comprehensive insight report on investigations carried out in addressing radiological safety measures of Ghana's Miniature Neutron Source Reactor (MNSR) during the going core conversion project. The amounts of Strontium-90 (Sr-90) and Krypton-85 (Kr-85) effluents presumably released from the reactor hall to the surroundings and the consequential emission radiation to the working area within a $200 \mathrm{~m}$ radius were analyzed for a six-month working period. The idea was to estimate specifically the approximate total effective dose equivalent (TEDE) value of Sr-90 and Kr-85 release and its effect by considering a conjectural accident scenario using the most reliable atmospheric dispersion code before the preparatory period.

Lack of proper account on radiation dose assessment for a nuclear facility has been an issue for the nuclear industry due to the longstanding health concern in relation to radiation exposure. This study adopted the most current basic approach based on Regulatory Guides from U.S. Nuclear Regulatory Commission (USNRC) for estimating radionuclide releases to the environment [7]. The accuracy in estimating the consequences of any radiological accident in terms of concentration and release doses mainly depends on the use of better and more reliable dispersion model.
Computer simulation codes which are more reliable, topographical specific, and meteorological dependent were employed in analyzing the hypothetical accident scenario and effect resulting from GHARR-1 core. To ascertain the amount of radionuclides present in the HEU fuel, core depletion analysis was carried out using a core depletion code. A core depletion code (ORIGEN2) was employed to estimate the burn-up of fuel and buildup of plutonium and fission products, a phenomenon termed as "source term analysis." This was perfectly carried out by analyzing the isotopic inventory of the HEU core. The objective for the source term analysis or estimation was to ascertain the presence of all possible radionuclide in the core.

Another vital issue when it comes to safety assessment of nuclear reactors is the dealing of dispersion of released radionuclides during accident situation, whether under normal or under abnormal operation conditions. As such, modeling of atmospheric dispersion has been considered as the first step for such assessments [3]. Although there has been improvement in atmospheric dispersion modeling computation power, not all atmospheric dispersion models are applicable to situations associated with radionuclides release [8]. Usually, atmospheric dispersion modeling and radionuclides release dose estimations are mostly evaluated after core depletion analysis process. The adopted atmospheric code employed in this work is the health physics code (HotSpot 3.0); its operation is based on Gaussian plume model for transport of effluence [9]. The code has been found to be useful since it is possible in predicting the pollution concentration at ground level [10].

1.1. Brief Description of Ghana MNSR. The finding of theis studies is based on Ghana's MNSR, a $30 \mathrm{~kW}$ tank-in-pool type research reactor with HEU fuel. The Ghana Research Reactor-1 (GHARR-1) is a commercial version of the Miniature Neutron Source Reactor (MNSR) and belongs to the class of pool-in-tank type reactors [11]. The thermal power rate of the facility is $30 \mathrm{~kW}$ with a corresponding peak thermal neutron flux of $1.0 \times 10 \mathrm{E} 12 \mathrm{n} / \mathrm{cm}^{2} \cdot \mathrm{s}$ [12]. Cooling is achieved by natural convection using light water. Presently, the GHARR-1 core consists of a fuel assembly of HEU (UAl alloyed) fuel elements arranged in ten concentric rings in a central control rod guide tube, which houses the reactor's only control rod. The control rod reactivity worth is about $7 \mathrm{mk}$, providing a core shutdown margin of $3 \mathrm{mk}$ of reactivity. The reactor control is accomplished with the help of a single centrally located control rod. The small core has a low critical mass. However, its relatively large negative temperature coefficient of reactivity is capable of boosting its inherent safety properties [13]. The small size of the core facilitates neutron leakage and escapes in both axial and radial directions. To minimize such loss and thereby conserve neutron economy, the core is heavily reflected, respectively, on the side and underneath the fuel cage by a thick annulus and slab of beryllium alloy material. The MNSR has recently found enormous application in various fields of science [12] particularly in trace elements in matrices of biological and environmental samples [14] and soil 
fertility studies and geochemical mapping [15]. Its reactor became critical and attained its rated power in November 1994. The reactor core comprises 344 fuel pins which are arranged in concentric arrays to form a cylindrical core as shown in Figures 1 and 2. Figures 1 and 2 are the core configuration showing fuel region and vertical cross section of GHARR-1, respectively.

The reactor core is located inside an aluminum vessel which is suspended in an underground pool. Two independent demineralization systems are provided to maintain the quality of the water in the vessel and the pool within the acceptable limits.

The reactor facility has a gas purge system located outside the main reactor hall that provides a mean of removing gases like ${ }^{41} \mathrm{Ar}$ accumulated in the empty space over the reactor. For experimentation, ten irradiation sites are provided, five inner irradiation sites and five outer irradiation sites. Thermal neutron flux levels of $1 \times 10^{12} \mathrm{n} / \mathrm{cm}^{2} \cdot \mathrm{s}$ and $5 \times 10^{11} \mathrm{n} / \mathrm{cm}^{2} \cdot \mathrm{s}$ are available in the inner and the outer irradiation sites, respectively, at the rated power. Reactor safety is ensured by its inherent characteristics which are imparted by its low excess reactivity, undermoderated core design, and negative temperature coefficient of reactivity. Reactor can be operated either in a manual or automatic mode through a conventional console desk or by a microcomputer-based control system. Reactor is operated on demand for training of students in reactor physics experiment and neutron activation analysis (NAA).

\section{Computational Methodology}

Source term analysis, radionuclide dispersion analysis, and estimation of radiation dose were carried out using two stateof-the-art codes: the ORIGEN2 and the Hotspot 3.0. Code (a Gaussian dispersion and dose estimation code). The ORIGEN2 code was used for core depletion analysis in determining the available radionuclides in the core of the MNSR. The code was used to calculate the activity and photon flux of the fuel during burn-up and the cooling time [17]. Before the start, the WIMS-ANL code was used for burn-up analysis although the library of the ORIGEN2 code has been developed for the Ghana MNSR with a cross-sectional data containing the MNSR fuel type. This was done to ascertain the accuracy of the code with respect to the Ghana MNSR. All factors related to the fuel geometry and the neutron spectrum were treated in WIMS-ANL.

Burn-up calculations of the fuel lattice cells were performed from the beginning to the burn-up of about $15 \%$ loss of U-235 for the HEU fuel. The heavy nuclides of the fuel burn-up-dependent microscopic cross sections were all collapsed from 69 energy groups to one energy group and later used in the ORIGEN2 code for core depletion analysis. The estimated depleted radionuclide of greater health consequence was used in the HotSpot code for gamma dose estimation and determination of plume dispersion rate.

2.1. Source Term Analysis. The ORIGEN2 code was extensively used for the core depletion analysis to study the burn-up of the fuel and the amount of radionuclides present in the core [18]. The code has been found to be comprehensively used in both research and power reactors for statics calculations and also in the solution of formation and disappearance of a nuclide by nuclear transmutation and radioactive decay method. The ORIGEN2 code is a one-dimensional neutron transport code capable of calculating the time-dependent formation, destruction, and decay of radionuclides. Also, the code was chosen or considered due to its faster convergence factor and does calculation on all possible fission products along the chain.

In general, the rate at which the amount of nuclide $\mathrm{N}_{i}$ changes as a function of time $\left(\mathrm{d} N_{i} / \mathrm{d} t\right)$ is described by a homogeneous differential equation as follows:

$$
\frac{\mathrm{d} N_{i}}{\mathrm{~d} t}=(\text { formation rate })-(\text { destruction rate })-(\text { decay rate }) .
$$

By considering the radioactive disintegration and neutron absorption [19], the time rate of change of concentration for particular nuclide, $\mathrm{N}_{i}$, is given as follows:

$$
\begin{aligned}
\frac{\mathrm{d} N_{i}}{\mathrm{~d} t}= & \sum_{j} \gamma_{j i} \sigma_{\mathrm{f} \cdot j} N_{j} \phi+\sigma_{\mathrm{c}, i-1} N_{i-1} \phi+\lambda_{i}^{\prime} N_{i}^{\prime}-\sigma_{\mathrm{f}},{ }_{i} N_{i} \phi \\
& -\sigma_{\mathrm{c}, i} N_{i} \phi-\lambda_{i} N_{i},
\end{aligned}
$$

where $i=1$, I, and $\sum_{j} \gamma_{j i} \sigma_{\mathrm{f} . j} N_{j} \phi$ is the yield rate of $\mathrm{N}_{i}$ due to the fission of all nuclides $N_{j}, \sigma_{c}^{j},{ }_{j-1} N_{i-1} \phi$ is the rate of transmutation into $N_{i}$ due to the radioactive decay of neutron capture by nuclide $N_{i-1}, \lambda_{i}^{\prime} N_{i}^{\prime}$ is the rate of formation of $\mathrm{N}_{i}$ due to the radioactive decay of nuclides $N_{i}^{\prime}$ and $\sigma_{\mathrm{f}},{ }_{i} N_{i} \phi$ is the destruction rate of $\mathrm{N}_{i}$ due to the fission, $\sigma_{c, i} N_{i} \phi$ is the destruction rate of $\mathrm{N}_{i}$ due to all forms of neutron absorption other than fission $((n, \Gamma),(n, \alpha),(n, p),(n, 2 n),(n, 3 n))$, and $\lambda_{i} N_{i}$ is the radioactive decay rate of $\mathrm{N}_{i}$.

2.2. The Dispersion Model Analysis. The greatest overall uncertainty in estimating the effects of radionuclides release arises from dynamic character of the atmosphere. Frequent shifts of wind direction and changes in stability and wind speed make it quite difficult to predict the area where the plume will move [20]. In a Gaussian dose model, a Gaussian distribution is assumed within the plume, and this results in complicated expression for the dose rate containing triple integral over three coordinate directions $[3,21]$ :

$$
\begin{aligned}
D_{\gamma}\left(x_{\mathrm{o}}, y_{\mathrm{o}}, z_{\mathrm{o}}\right)= & \frac{\mathrm{KE}_{\gamma} \mu_{\mathrm{a}}}{\rho} \int_{0}^{\infty} \int_{-\infty}^{\infty} \int_{0}^{\infty} \\
& \cdot \frac{\mathrm{B}\left(\mathrm{E}_{\gamma}, \mu r\right) \exp (-\mu r) \chi\left(x^{!}, y^{!}, z^{!}\right) \mathrm{d} x^{!}, \mathrm{d} y^{!}, \mathrm{d} z^{!}}{4 \pi r^{2}} .
\end{aligned}
$$

The concentration of radionuclides in a plume having Gaussian distribution may be calculated by the Gaussian plume model [22]: 


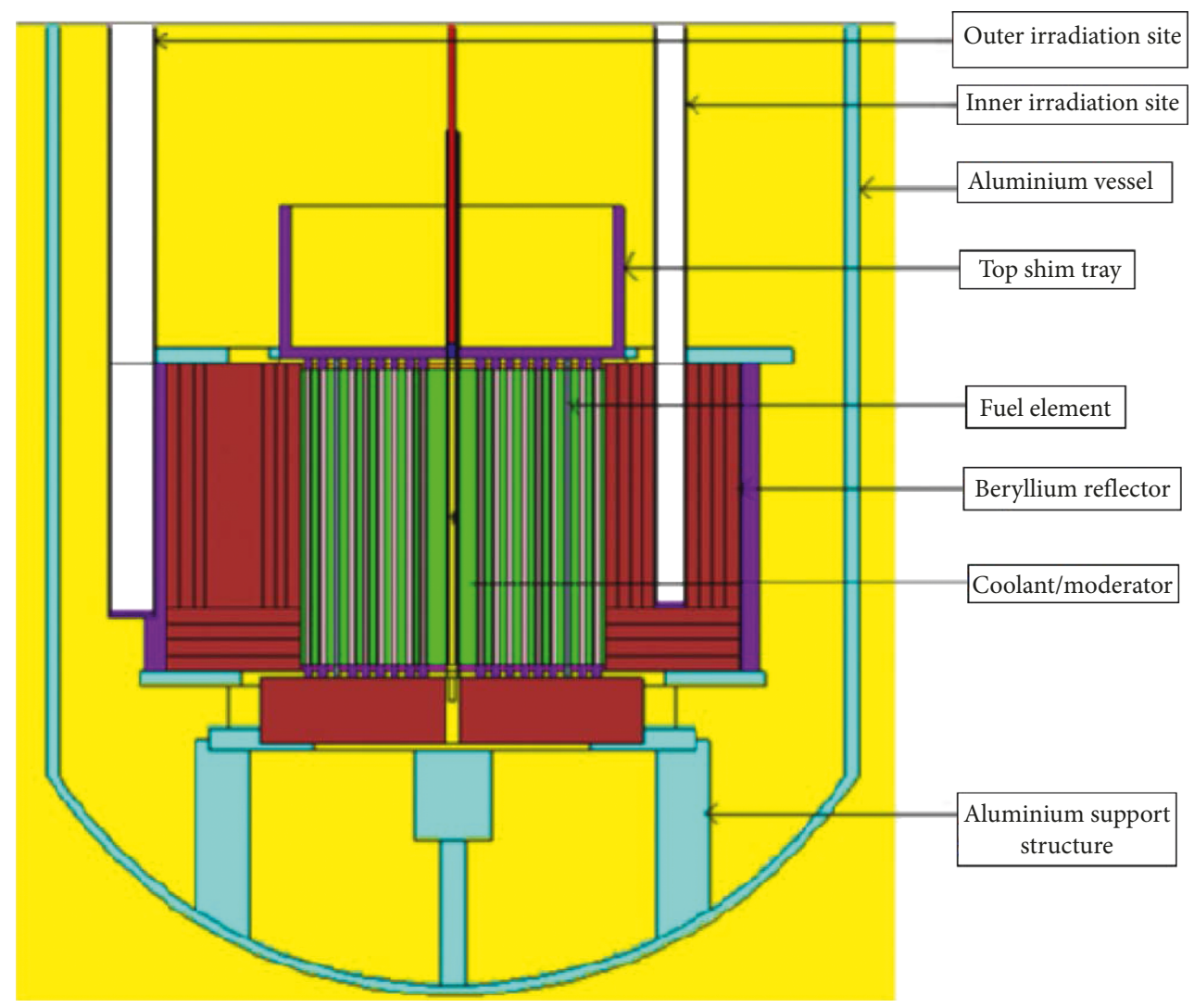

FIgURE 1: Vertical cross-sectional view of the GHARR-1 reactor.

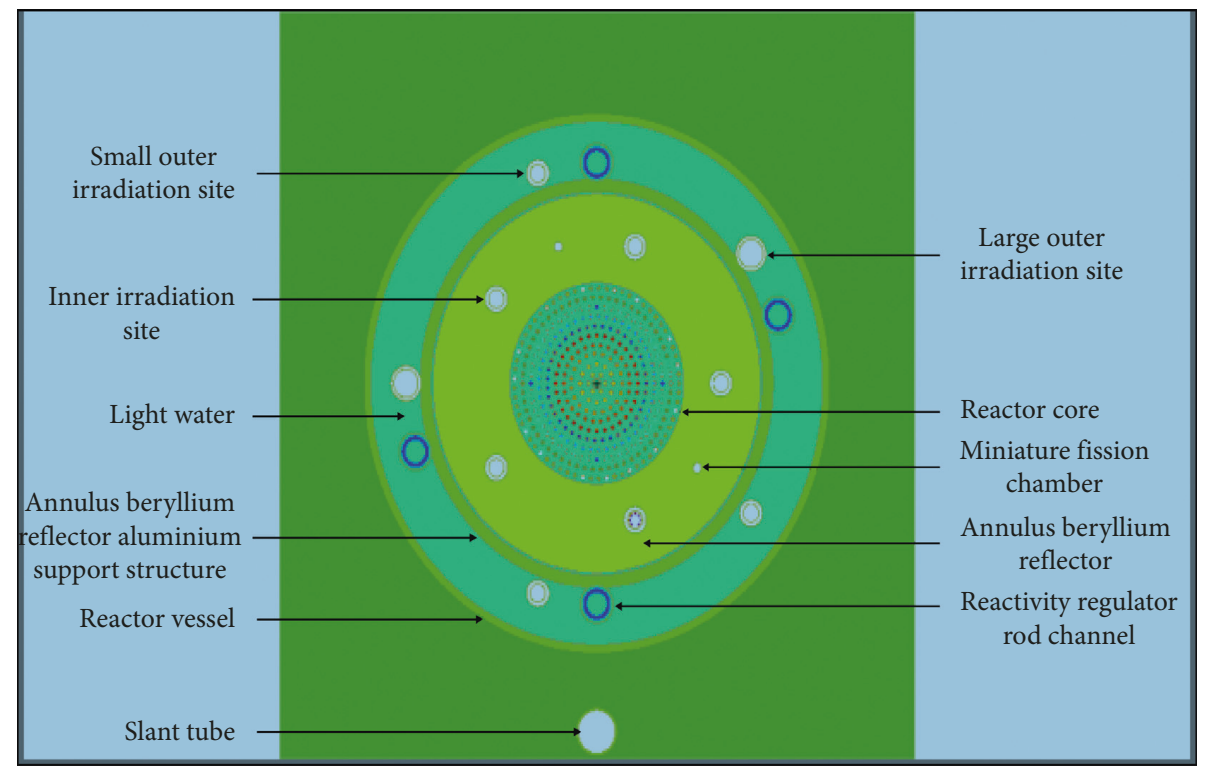

FIgURE 2: Core configuration of the GHARR-1 reactor [16]. 


$$
\begin{aligned}
\chi(x, y, z ; H)= & \frac{Q}{2 \pi \mu \sigma_{y} \sigma_{z}}\left[\exp -\left(\frac{y^{2}}{2 \sigma_{y}^{2}}\right)\right] \\
& \cdot\left\{\exp \left[\frac{-(z-H)^{2}}{2 \sigma_{z}^{2}}\right]+\exp \left[\frac{-(z+H)^{2}}{2 \sigma_{z}^{2}}\right]\right\},
\end{aligned}
$$

where $Q_{0}$ is the radioactivity release rate $\left(\mathrm{Bq} \cdot \mathrm{s}^{-1}\right), u$ is the mean wind $\left(\mathrm{m} \mathrm{s}^{-1}\right)$ at release height $(\mathrm{m})$, and $h, \sigma_{y}$, and $\sigma_{z}$ (m) are coefficients of atmospheric dispersion along the horizontal and vertical directions.

\section{Site-Specific Meteorological Conditions}

Data from the Ghana Meteorological Agency (GMet) [23] database based on the site of the facility were used for the dose estimation. The average wind speed observed in the sixmonth period was $4.1 \mathrm{~m} / \mathrm{s}$, the estimated average maximum temperature record in June was $29.6^{\circ} \mathrm{C}$, and the wind direction was southeast. These were some of the input parameters used in the code. It is usually important to consider stability classes when analyzing dispersion of releases. It is a requirement because it helps during the quantification of dispersion capabilities of ambient atmosphere for the concentration predictions of air quality models. The main stability classes used in this work are as presented in Table 1.

From the meteorological point of view, the degree of atmospheric stability is directly related to the vertical gradient of temperature as well as the horizontal wind speed. Unstable atmospheric conditions are usually as a result of large negative gradient. With respect to neutral and stable conditions, their effects are as a result of negative and positive temperature gradients, respectively. The selected classes used in these studies are summarized in Table 1.

\section{Methodology}

The studies were carried out by first predicting available radionuclides in the HEU fuel by carrying out core depletion analysis. The end-of-cycle (EOC) values of inventory and corresponding activities of various radionuclides of regulatory concern (Sr-90 and $\mathrm{Kr}-85$ ) were used in the dispersion code for dose calculation. This was done by predicting possible postulated conjectural initiation event.

4.1. Generation of Source Term. Estimation of the source term was carried out using ORIGEN2 code. An input deck was set up to determine the isotopic core inventory of the HEU fuel. The nuclide composition and continuous nuclide feed rate were specified for nuclides of interest. The decay and cross section libraries were specified so that the code works with the selected data. The deck was also set up to track photon production rate in 39 energy groups. The average burn-up, flux, and specific power for an irradiation were calculated. The power history of the MNSR used was $15 \mathrm{~kW}$. The flux spectrum of the reactor which was obtained from a preprocessed cross section from MCNP was used.
TABLE 1: The three most selected Pasquill-Gifford stability classes based on the site condition.

\begin{tabular}{lccc}
\hline Description & Stability class & Time of day & $\begin{array}{c}\text { Wind speed } \\
(\mathrm{m} / \mathrm{s})\end{array}$ \\
\hline Strongly unstable & A & Sunny day & $<2$ \\
Moderately unstable & B & Sunny day & $3-4$ \\
Slightly unstable & C & Sunny day & $4-6$ \\
\hline
\end{tabular}

4.2. Conjectural Initiating Event (HIE) Predicted. In the scenario, it was postulated that in the attempt of lifting the core from the reactor vessel using the overhead crane something unusual happened. It was assumed that the crane hook swung to the left direction resulting in the core hitting the metal rail and disengaging when it has lifted the core almost through the reactor vessel. By gravity, the core falls to the bottom of the vessel causing mechanical damage in several pins of the 344 fuel pins. It was assumed that the incident resulted in a release of radionuclide to the reactor hall whose exhaust ventilation system and gas purge system are turned off. The operation team members tried to salvage the situation by pumping water back into the reactor vessel and the pool from the deionizing hall as both vessel and pool water levels were tremendously reduced during the process. The slow pace flow of the water could not salvage the situation as radiation from the reactor core escaped through the reactor building stack in the form of gas and particulate as it diffuses into the atmosphere.

4.3. Evaluation of Radiation Dose. The calculated values of the end-of-cycle (EOC) inventory of the available radionuclides along with their activities and release fraction for the selected radionuclides are given in Table 2 . The physical properties, chemical properties, radiotoxicity, and the harm they can cause to human health and regulatory requirement were the reasons for the selection of the radionuclides. Strontium-90 is a $\beta$-emitter, mobile, volatile, and readily taken up in the food chain. Since Strontium-90 is a betaemitting radionuclide, its contact with the skin surface causes damage to the epithelial basal stratum due to beta irradiation. Bone tumors (osteosarcomas) are associated with Strontium-90 due to its bone-seeking affinity. Strontium ions can exchange with the calcium in the mineral matter; they thereby are deposited within the mineralized bone area and into the epiphysis and are believed to contribute to bone cancer and leukemia. Although $\mathrm{Kr}-85$ is used in pneumatology, it also has a serious effect on body tissues. A direct contact by the body as well as inhalation can lead to serious breathing problems. Excessively inhalation of $\mathrm{Kr}-85$ concentrations usually results in dizziness, nausea, vomiting, loss of consciousness, and even death.

A health physics code from Lawrence Livermore National Laboratory (HotSpot 3.0) was used as a computational tool for dose estimation [9]. The dose estimations were based on the following hypothetical assumption.

\section{Assumption:}

(a) Fission products released escape from the building through the stack at air flow rate of $450 \mathrm{~m}^{3} \cdot \mathrm{h}^{-1}$, based on the reactor size. 
TABLE 2: Some selected radionuclide inventory in the HEU core at reactor shutdown.

\begin{tabular}{lccc}
\hline Radionuclide & Group & Activity of inventory $(\mathrm{Bq})$ & Release fraction \\
\hline Sr-90 & Br-Sr group & $7.133 E+07 \mathrm{~Bq}$ & 0.3 \\
$\mathrm{Kr}-85$ & Noble gas & $1.880 E+02 \mathrm{~Bq}$ & 0.04 \\
\hline
\end{tabular}

TABLE 3: Summary of hypothetical assumption applied.

\begin{tabular}{lr}
\hline Material & Sr-90 and Kr-85 \\
\hline Material-at-risk (MAR) & $1.8800 E+02 \mathrm{~Bq}$ \\
Source damage ratio (DR) & 1.00 \\
Airborne fraction (ARF) & 1.000 \\
Respirable fraction (RF) & 1.000 \\
Leak path factor (LPF) & 1.000 \\
Respirable source term & $1.88 E+02 \mathrm{~Bq}$ \\
Nonrespirable source term & $0.00 E+00 \mathrm{~Bq}$ \\
\hline
\end{tabular}

TABle 4: Maximum TEDE values for some selected radionuclides at different atmospheric stability classes.

\begin{tabular}{lccr}
\hline Atmospheric stability class & Sr-90 TEDE $(\mathrm{mSv})$ & Kr-85 TEDE (mSv) & Maximum distance (km) \\
\hline A & $1.80 E-02$ & $4.94 E-4$ & 0.10 \\
B & $1.45 E-02$ & $4.09 E-4$ & 0.10 \\
C & $\mathbf{1 . 8 0 E}-\mathbf{0 2}$ & $\mathbf{4 . 9 0 E}-\mathbf{4}$ & $\mathbf{0 . 1 0}$ \\
\hline
\end{tabular}

(b) The wind (speed $4.1 \mathrm{~m} / \mathrm{s}$ ) transported the radionuclides release point to downwind receptor locations, towards the most predominant wind direction at the site. Table 3 presents other assumptions that were considered in this study.

\section{Result and Discussion}

Table 4 shows the maximum distances and the corresponding estimated dose values of the selected radionuclides at different stability classes. The results clearly show that the accumulated inventory activity value for the HEU had some effect on the dose values by a margin of $1 \%$.

The slight difference in values can be attributed to difference in stability classes used. The variation of dose level at various distances is shown in Figures 3 and 4 for Sr-90 and $\mathrm{Kr}-85$, respectively. On no account did the study consider inversion layer height; all the computations were performed under a Pasquill-Gifford stability classes A, B, and C.

The results indicate that the more unstable the meteorological conditions that prevail, the higher the value of TEDE for a shorter distance and vice versa. The dependence of plume rise on downwind distance from the stack predicts a curve as formulated by Briggs [24]. The maximum dose values obtained are below the acceptable limit of the $1 \mathrm{mSv}$ for the public and $50 \mathrm{mSv}$ for the radiation worker in [25-27]. The probable affected areas by the plume contour line (path) of the radionuclide emission are as shown in Figure 5.

The graphical representation of $\mathrm{Sr}-90$ and $\mathrm{Kr}-85$ isotopes for the stability class C, slightly unstable, is as presented in Figures 3 and 4 . The radiation dose rises to a maximum distance of about $0.10 \mathrm{~km}$ and then decreases steadily as shown in the figures. The rise is due to the specific weather

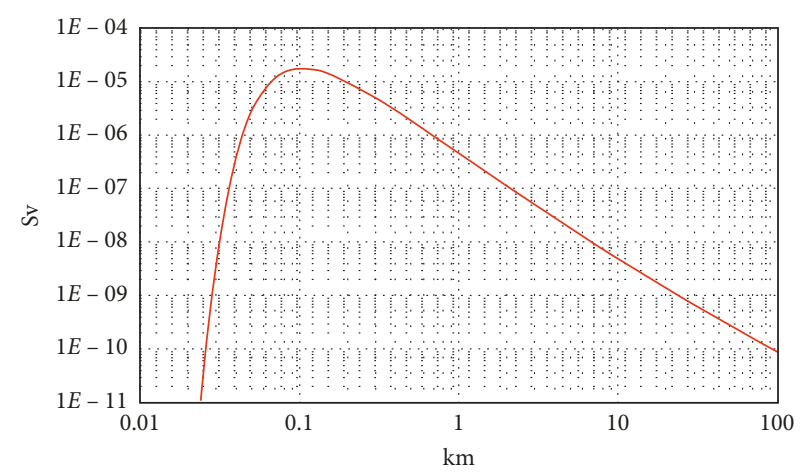

Figure 3: Total effective dose equivalent (TEDE) as a function of receptor downwind distance of Sr-9 for stability class C.

condition and the prevailing wind situation. The dose concentration profiles for the ground deposition dose rates are presented in Table 5 for the released Sr-90 and $\mathrm{Kr}-85$ isotopes. These values are obtained at different times as radionuclides reach the designated receptor points at downwind locations.

The outcome of the result shows a decrease in the TEDE when meteorological stability conditions become more stable and result in a shift at longer distances. The turbulence in the unstable atmosphere brings the plume to the ground very quickly. An unstable atmosphere increases the amount of vertical spreading and creates loops that move the plume up and down in the atmosphere, thereby increasing the ground concentration every time the plume reaches the ground. However, farther downwind concentrations drop very quickly. The stable atmosphere, on the other hand, has a much lower peak. Hence, the TEDE and the ground surface 


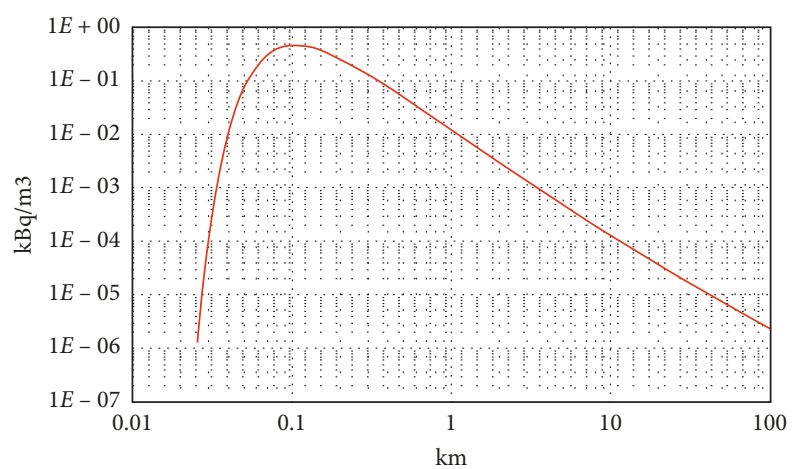

FIGURE 4: Kr-85 plume centerline total effective dose equivalent (TED) as a function of receptor downwind distance for stability class C.

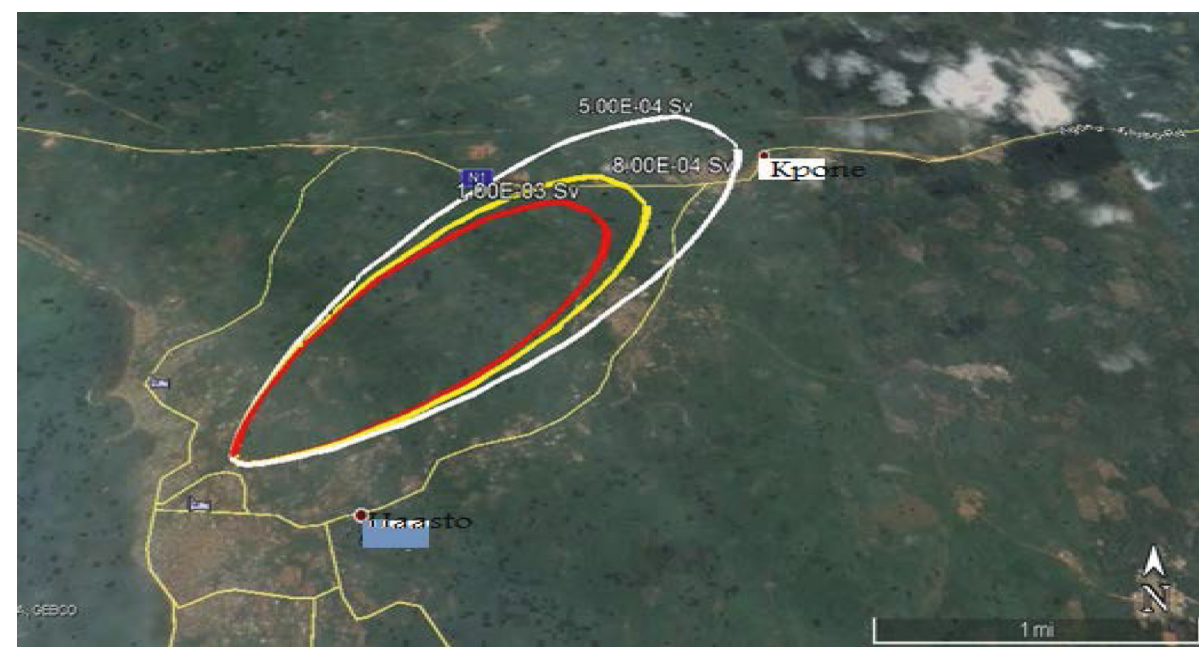

Figure 5: Plume contour showing areas that fall within the path of the radionuclide emission.

TABLE 5: Total effective dose and other plume centerline parameters at different arrival times.

\begin{tabular}{lcccc}
\hline Distance $(\mathrm{Km})$ & TEDE for Sr-90 (Sv) & TEDE for Kr-85 (Sv) & Ground surface deposition for Sr-90 $\left(\mathrm{KBq} / \mathrm{m}^{2}\right)$ & Arrival time (hour:min) \\
\hline $\mathbf{0 . 1 0 0}$ & $\mathbf{1 . 8 E - \mathbf { 0 5 }}$ & $\mathbf{4 . 9 E - \mathbf { 0 7 }}$ & $\mathbf{4 . 6 E - \mathbf { 0 1 }}$ & $00: 01$ \\
0.200 & $9.9 E-06$ & $2.9 E-07$ & $2.5 E-01$ & $00: 03$ \\
0.300 & $5.0 E-06$ & $1.5 E-07$ & $1.3 E-01$ & $00: 05$ \\
0.400 & $2.9 E-06$ & $8.9 E-08$ & $7.5 E-02$ & $00: 07$ \\
0.500 & $1.9 E-06$ & $5.9 E-08$ & $4.8 E-02$ & $00: 09$ \\
0.600 & $1.3 E-06$ & $4.2 E-08$ & $3.4 E-02$ & $00: 11$ \\
0.700 & $9.6 E-07$ & $3.1 E-08$ & $2.5 E-02$ & $00: 13$ \\
0.800 & $7.3 E-07$ & $2.4 E-08$ & $1.9 E-02$ & $00: 13$ \\
0.900 & $5.8 E-07$ & $1.9 E-08$ & $1.5 E-02$ & $00: 17$ \\
1.000 & $4.7 E-07$ & $1.6 E-08$ & $1.2 E-02$ & $00: 019$ \\
\hline
\end{tabular}

deposition (in $\mathrm{kBqm}^{-2}$ ) for Sr-90 were estimated. However, the ground level concentration was not calculated for Kr-85, as it is assumed that all the noble gas isotopes are released into the atmosphere and not deposited on the ground below. This important characteristic behavior of noble gases is that they do not deposit following release to the atmosphere.

The distribution of target organ committed dose to some selected organs as a function of downwind is shown in Figure 6. From the estimated result, it shows that the lung is the most body tissue to be affected, followed by the bone, thyroid gland, brain, and red marrow, respectively, under the postulated scenario.

The HotSpot code calculates committed effective dose equivalent (CEDE) by integrating the committed dose equivalents throughout 50 years for different tissues and organs of the body, and an appropriate multiplication factor $W_{\mathrm{T}}$ has been used for each committed dose equivalent. The distribution of CEDE to different organs as a function of downwind distance is shown in Figure 6. It can be deduced that these six organs are more radiation sensitive than the 


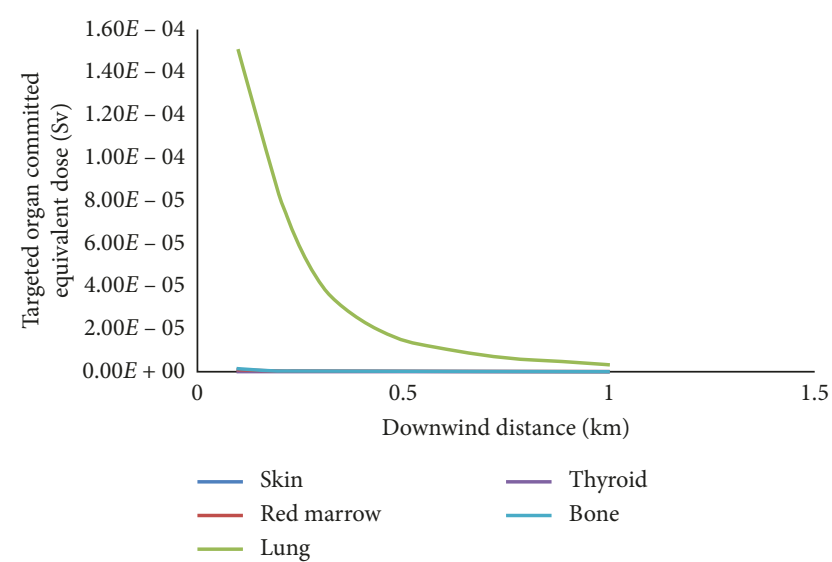

FIGURE 6: Target organ committed equivalent dose as a function of downwind location.

others. The CEDE plots for all the target organs have similar Gaussian trend, as they diminish with distance from the release point.

TEDE for a given exposure depends on intake and retention of various radionuclides, the possibility of concentration in the body organs, and the radiological half-life of the nuclide.

\section{Conclusions}

The concerns of international bodies and other organizations on the use of HEU fuel powered reactors for peaceful purposes have compelled the research into core conversion studies. Although the study was on HEU, the methodology will help develop better emergency plan for LEU cores for the MNSR that will ensure desirable power and flux. There should have been a baseline value for dose assessment for GHARR-1 in an event of accident. Results from this study can be used as a baseline measure for any emergency situation during the reactor lifetime. The impacts of Sr-90 and $\mathrm{Kr}-85$ release from the MNSR following a conjectural accident scenario were found to be very low as expected by the nuclear regulators. The estimated total activity was $7.133 E+07 \mathrm{~Bq}$ and $1.880 E+02 \mathrm{~Bq}$ for Sr-90 and Kr-85, respectively, accounting for a low TEDE in $\mathrm{mSv}$ of $1.8 E-02$ for $\mathrm{Sr}-90$ and $4.9 E-4$ for $\mathrm{Kr}-85$ at a maximum distance of $0.1 \mathrm{~km}$ for a stability class $\mathrm{C}$. The estimated dose values recorded were found to be within the recommended regulatory safety limits of $50 \mathrm{mSv}$ for onsite workers and $1 \mathrm{mSv}$ for the general public. No adverse effect was experienced with respect to human health and the environment. The studies have provided a comprehensive insight report on addressing radiological safety measures. The studies procedures and results have paved the way for the operator to establish proper emergency plans and counter measures to be used after the installation of the LEU fuel. The dose results estimated from the dispersion code were found to be in good agreement with other research findings. There were some slight differences in values as compared to other research works carried out within the facility. The differences may be due to the time period, operating condition, and weather condition at the time. A more comprehensive study of the release and pathways would have been carried on should the dose values exceed the annual dose value for workers and the general public. Since the estimated dose values are very low in approximation, the margin of error due to the simulation did not significantly alter the final results significantly. With a good degree of reliability, the conjectural accident scenario as proposed in this research would not constitute any radiological effect on the site, workers, and the populace. The outcome result from the study has proven that the whole core conversion program can be credible without any problem with respect to safety.

\section{Data Availability}

All data used are obtained from our own research work and those obtained somewhere have approval from the source.

\section{Conflicts of Interest}

The authors declare that they have no conflicts of interest.

\section{Acknowledgments}

The authors appreciate the support of the Ghana Atomic Energy Commission for financial assistance in purchasing the code and allowing the research team use their research reactor for the study.

\section{References}

[1] E. H. K. Akaho, "Ghana research reactor-1 safety analysis report, revised version," Ghana atomic energy technical report, GAEC-NNRI-RT, GAEC, Accra, Ghana, 2003.

[2] A. Schaper, Highly Enriched Uranium, a Dangerous Substance that Should Be Eliminated, Peace Research Institute Frankfurt (PRIF), Frankfurt, Germany, 2013.

[3] S. S. Raza and M. Iqbal, "Atmospheric dispersion modeling for an accidental release from the Pakistan research reactor-1 (PARR-1)," Annals of Nuclear Energy, vol. 32, no. 11, pp. 1157-1166, 2005.

[4] J. Bell and N. Roskoff, Investigation into the Unintended Consequences of Converting the U.S. Nuclear Naval Fleet from Highly Enriched Uranium (HEU) to Low Enriched Uranium (LEU), Virginia Tech, Arlington, VA, USA, 2014.

[5] IAEA-TECDOC-1452, Management of high enriched uranium for peaceful purposes: status and trends, International Atomic Energy Agency, Vienna, Austria, 2005.

[6] IGORR, "Research Reactor Fuel Management (RRFM) and Meeting of the International Group on Reactor Research (IGORR)," in Proceedings of the 11th International Topical Meeting, Centre de Congrès, Lyon, France, March 2007.

[7] US-NRC, Alternative radiological source terms for evaluating design basis accidents at nuclear power reactors. Regulation Guide 1.183, Nuclear Regulatory Commission, Rockville, MD, USA, 2000.

[8] IAEA-TECDOC, Atmospheric Dispersion Models for Application in Relation to Radionuclide Releases, International Atomic Energy Agency, Vienna, Austria, 1986.

[9] S. G. Homann, HotSpot Health Physics Code, Version 3.0, User's Guide, LLNL-SM-483991, National Atmospheric 
Release Advisory Center, Lawrence Livermore National Laboratory, Livermore, CA, USA, 2011.

[10] A. A. Adel, "On the atmospheric dispersion and Gaussian plume model," in Proceedings of Meeting of the 2nd International Conference on Waste Management, Water Pollution, Air Pollution, Indoor Climate (WWAI'08), Corfu, Greece, 2008.

[11] J. Gao, General Description of the Ghana MNSR. MNSR Training, China Institute of Atomic Energy, Beijing, China, 1993.

[12] G. Kennedy, J. St-Pierre, K. Wang et al., "Activation constant for SLOWPLOKE and MNS reactors calculated from the neutron spectrum and k0 and Q0 values," Journal of Radioanalytical and Nuclear Chemistry, vol. 245, no. 1, pp. 167$172,2000$.

[13] B. J. B. Nyarko, Neutron Activation Analysis, University of Ghana, School of Nuclear and Allied Sciences, Department of Nuclear Engineering, Accra, Ghana, 2009.

[14] T. Su-De, "Multi-elemental analysis of Chinese biological standard reference materials by mono standard instrumental neutron activation analysis," Journal of Radioanalytical and Nuclear Chemistry, vol. 81, 1984.

[15] I. Umar, "The potentials of MNSR in the socioeconomic development of Nigeria," in ICENSIAEA Small Research Reactor Workshop, University of West Indies, Kingston, Jamaica, 2003.

[16] B. Osei, "Theoretical characterization of irradiation sites of Ghana research reactor-1 with low enriched uranium," in Proceedings of Meeting of the 9th African Conference on Research Reactor Utilization and Safety, Accra, Ghana, 2017.

[17] S. Ludwig, Revision to ORIGEN2-Version 2.2, Oak Ridge National Laboratory, Oak Ridge, TN, USA, 2002.

[18] A. G. Croff, A User Manual for the ORIGEN2 Computer Code, Oak Ridge National Laboratory, Oak Ridge, TN, USA, 1980.

[19] O. W. Hermann and R. M. Westfall, ORIGEN-S: SCALE System Module to Calculate Fuel Depletion, Actinide Transmutation, Fission Product Buildup and Decay, and Associated Radiation Source Terms, ORNL/NUREG/CSD-2/V2/R6.Revision 6, Section F7, 1998.

[20] R. Macdonald, Theory and Objectives of Air Dispersion Modeling, Department of Mechanical Engineering, University of Waterloo, Waterloo, Canada, 2003.

[21] T. J. Overcamp and R. A. Fjeld, "A simple approximation for estimating centerline gamma absorbed dose rates due to a continuous Gaussian plume," Health Physics, vol. 53, no. 2, pp. 143-146, 1987.

[22] C. H. Bosanquet and J. L. Pearson, "The spread of smoke and gases from chimney," Transactions of the Faraday Society, vol. 32, p. 1249, 1936.

[23] Ghana Meteorological Agency, "Ghana rainwatch," Report, Ghana Meteorological Agency, Accra, Ghana, 2018.

[24] G. A. Pearson, Plume Rise; U.S. Atomic Energy Commission Critical Review Series, Prepared for Nuclear Safety Information Center, Oak Ridge National Laboratory, Oak Ridge, TN, USA, 1969.

[25] International Commission on Radiological Protection, "Recommendations of the international commission on radiological protection, ICRP 60," Annals of ICRP, vol. 21, pp. 1-3, 1991.

[26] International Commission on Radiological Protection, "Human respiratory tract model for radiological protection, ICRP 66," Annals of ICRP, vol. 24, pp. 1-3, 1994.

[27] International Commission on Radiological Protection, "Age dependent doses to the members of the public from intake of radionuclides, ICRP 72," Annals of ICRP, vol. 26, p. 1, 1996. 

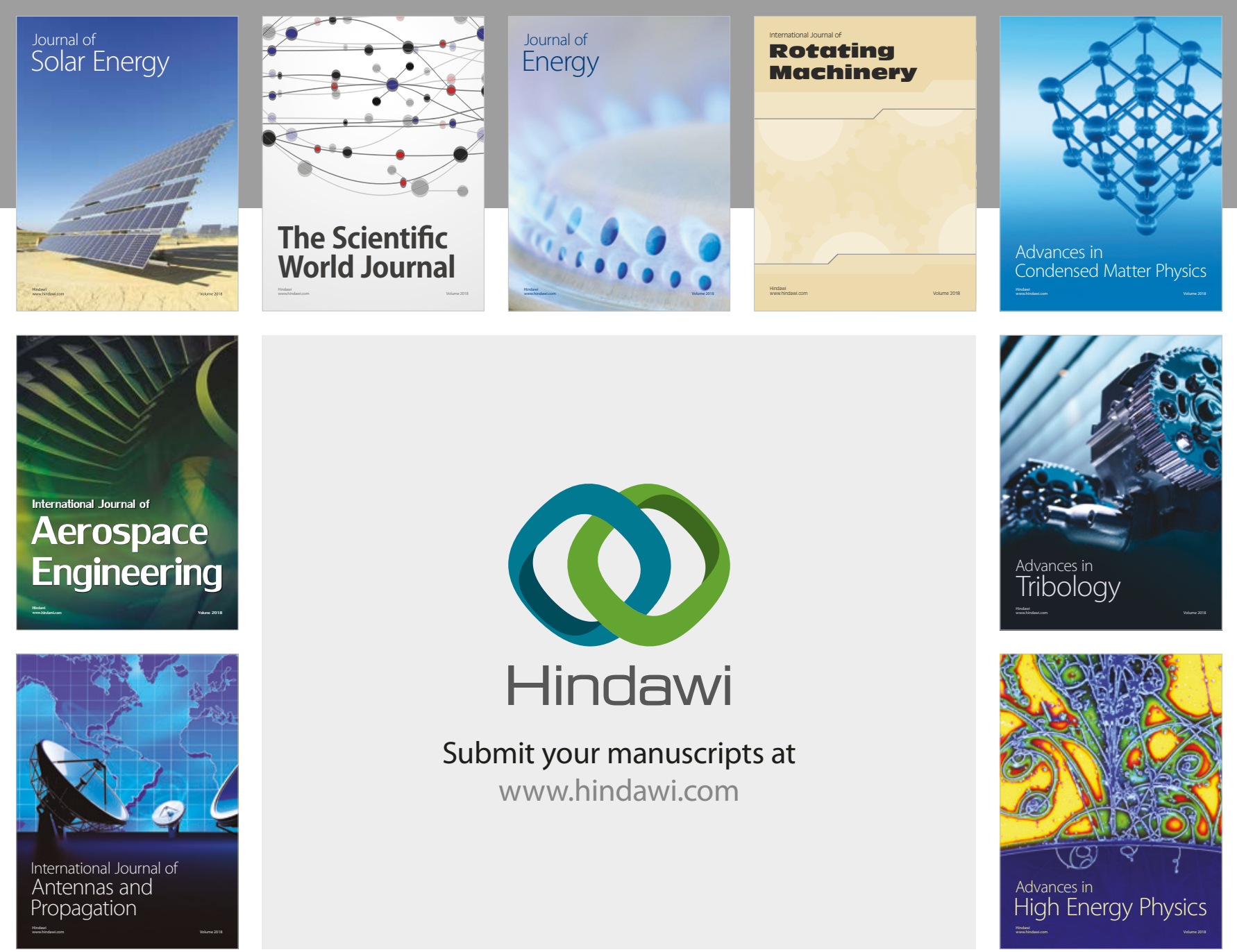

Submit your manuscripts at

www.hindawi.com
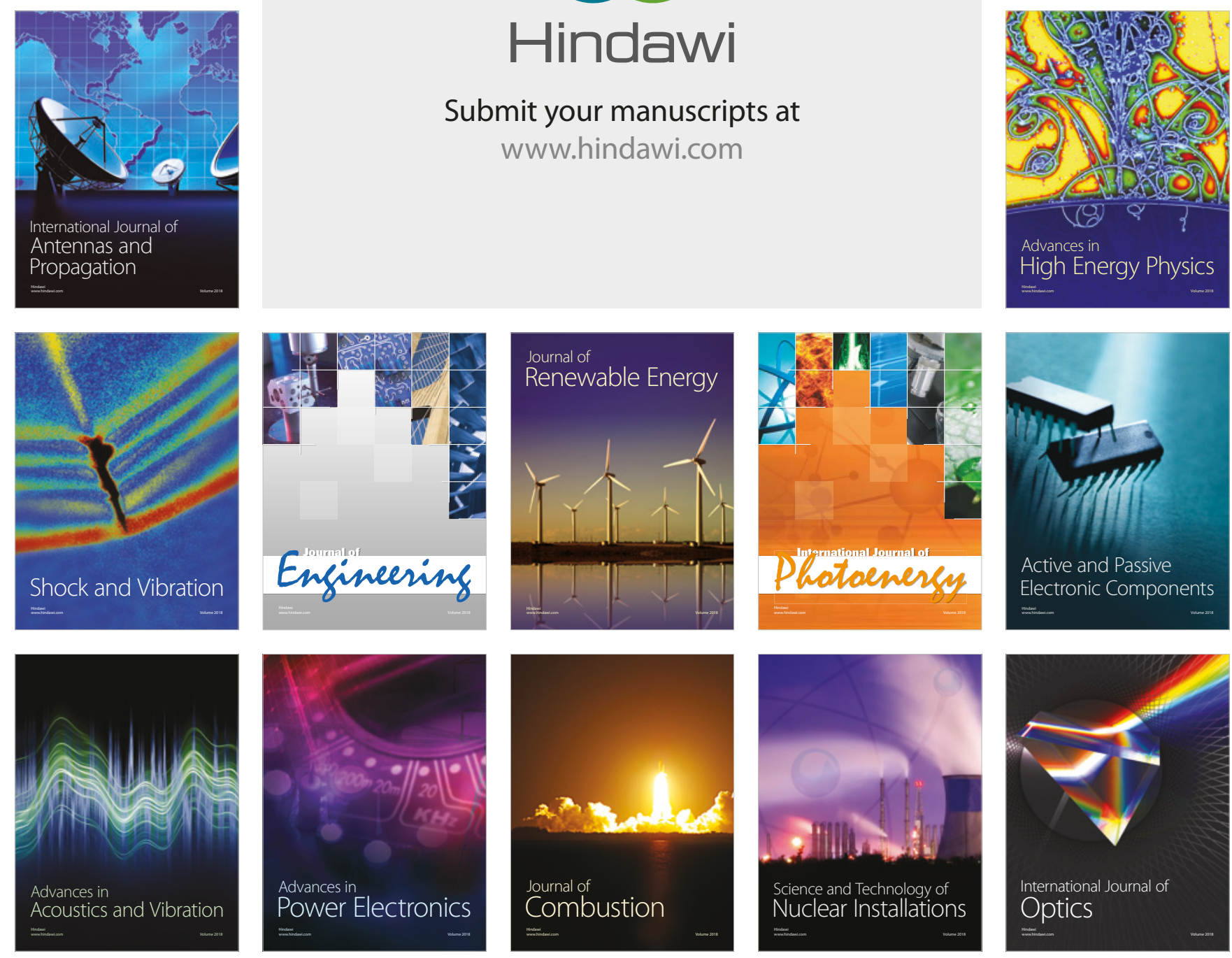